NOTE S

ox TH:

TREATMENT OF CURABLE DISEASES.

BY W. S. OK E, M.D.,

Rxtra-Licentiate of the Royal College of Physicians, Physician to the Royal South Hants Infirmary, \&c.

Ir is a remarkable feature of the present era of medicine in this country that a large number of medical practitioners-men who have been regularly educated in the established schools of physic;-men who, by virtue of the knowledge therein acquired, have obtained from authorised tribunals testimonials of their fitness to practise ; -men who are, therefore, morally pledged to uphold the character of their diplomas,-have unscrupulously forsaken the ranks of their profession to practise certain strange methods of cure which have sprung up in Germany under their respective founders Mesmer, Priessnitz, and Hahnemann.

It might be asked,-What is the cause of such delinquency? Is it to be found in any obvious superiority of the systems they have embraced, or in a general declension of the doctrines taught in the medical schools? Not in the former, for neither mesmerism, nor hydropathy, nor homœepathy is possessed of any principles which are entitled to the slightest respect; indeed some of their extravagancies, such as clairvoyance, globulism, \&c., are utterly ridiculous and contemptible. It cannot be occasioned by the latter, because there probably never was a period when the practice of medicine was carried out with more science, zeal, and success.

Whatever be the motive for such a line of conduct, it is deeply to be regretted that so many respectable men, whose talents might have shed a lustre upon the paths of their profession, should tarnish their reputation by practising quackeries, some of which they themselves must be conscious are not founded upon truth.

On the other hand, the character of medicine has nothing to fear from these alloys. It can neither be amalgamated with nor disparaged by them. There is no agreement betwixt light and darkness, and no union between truth and quackery; and whilst these novel empiricisms will not outlive the age that has given them birth, and will become the laughing-stock of the future, the legitimate practice of medicine will hold on its honourable cause, dispensing its varied benefits to the sick, and carrying with it the respect and confidence of the civilized world.

But these observations are not intended to attribute the superiority of practical medicine orer empiricism to the possession of mathematical laws. It is at once admitted that it is not a science in the highest sense of the term-that is, possessing certainties grounded on demonstration. Nevertheless it is a practical science, and has the power of conferring a large amount of benefit upon mankind; for although there are grievous diseases over which it has no curative control, and recoveries which cannot be called cures, there are some diseases which, humanly speaking, cannot be cured without it, many cures which are greatly promoted by it, and scarce a disease which cannot be in some measure alleviated by it. This has been achieved by experiment and observation, aided by the splendid discoveries in chemistry; and by this method only can it go forward in the hope of triumphing over some of those diseases which yet remain incurable. It is this which constitutes what is commonly called experienceso valuable to the medical man, and so valued by the public at large; for surely it will be allowed that the less demonstrative certainties we possess to produce therapeutic results the more experience we stand in need of to guide us in the fulfilment of curative indications. Every candid practitioner will, I believe, acknowledge this, when, in the discharge of his arduous duties, he is combating a disease which endangers the life of his patient and fills his own mind with painful anxiety.

Upon this ground I shall venture, from time to time, as opportunity may permit, to supply our Journal with some of the results of my own experience, in the hope of upholding, however feebly, the character of practical medicine-a character which it has fairly won in the paths of zeal, observation, and candour, and which it will never lose till it departs from them.

It is not presumed that the means which I linve found successful will always prove to be so in aspect- of disease apparently similar; because it too frequently happens that diseases which appear to be of a similar character will turn out to be in reality very different, and require a different mode of treatment ; nevertheless, when a given treatment $h_{h}$ as been found to be successful in a certain assemblage of symptoms, it may be recorded as one method of cure.

Defective Power of the Lower Extremities in the Second Year of Childhood.

This is a case which often comes under my observation, and which, I believe, has been overlooked. The child, instead of being able to stand at the usual time, is found to be unable to bear the weight of the body on its lower limbs, the muscles of which are in some degree wasted and flabby. Upon examining the spinal column in the sitting posture, a slight posterior curve of the inferior dorsal vertebræ will be discovered, which will at once indicate the cause of the want of power.

The following mode of treatinent I have commonly found successful :- A small blister about an inch and a half long by half an inch broad is to be applied on each side of the curve once in a fortnight; the sysi:m is to be supported by prescription No. 1 , and the bowels gently corrected once a week by No. 2 .

1.-R. Vini Ferri, m. xx.

Detur hoe dosis infanti bis quotidie ex aquæ pauxillo.

2.-R. Hydrargyri cum Cretâ, gr. ij.

Rhei Radicis Pulv., gr. iv.

Pulveris Cinnamoni Comp., gr. j.

Misce fiat dosis semel in septimanis sumenda. 
The child is never to be carried upright; and as it will be of great importance to take it into the open air in fine weather, it may be laid upon a small mattress in a concave wicker tray, which will be found light and convenient for the purpose. When left to itself it should be laid on a mattress either upon the floor or upon a bedstead; and this treatment should be continued until it regains sufficient power to attain the apright posture.

Case.-A lady, on discovering that the lower limbs of her child, although fifteen months old and of healthy appearance, always gave way under the weight of the trunk, brought it to me to ascertain the cause. On examining the spinal column I found a slight posterior curve of the spinous processes of the inferior dorsal and upper lumbar vertebræ. A small blister was ordered to be applied on each side of the curve, half a fluidrachm of the Vinum Ferri to be given twice a day, and strict directions were given that no further attempt should be made to induce the child to stand upon its feet for some time to come, and that it should be carried into the air in a recumbent position in a wicker tray. The result was, that in a few months it completely recovered the use of its legs, and went on well. Were it necessary, I could adduce very many cases of the same kind to prove the success of this mode of treatment.

The strength should be supported, if the child has been weaned, by equal parts of milk and barley gruel.

\section{Convulsions in Chimpren.}

Convulsions in children are most commonly brought on by reflex action, from some cause external to the brain, such as teething, crudities in the alimentary canal, \&c.; but they are sometimes the result of a congested state of the cerebral vessels, and, therefore, an early and correct diagnosis is of the highest importance. If they are occasioned by the former, there may be no antecedent cerebral symptoms to warn us of their approach; they will, probably, soon cease. And, moreover, some advancing teeth, or improper food, will perhaps at once manifest the exciting cause, and the method of cure. If from the latter, they will be preceded by symptoms of cerebral congestion, such as inaction of the bowels, a drowsy aspect, pain of the head, (if the child be old enough to express it, if not, the hands will be frequently carried there,) immobility of one or both pupils, involuntary movements of the eye-balls, and grinding of the teeth. Convulsions following these symptoms do not subside like those which are produced merely by the irritation of teething, or of crudities in the stomach ; and unless they are combated by a prompt and decided treatment, will continue till the brain becomes oppressed by serous infiltration, which is almost certain to end in insensibility, profuse sweats, intermittent breathing, and death. In this case we ought not to wait for the bleeding of leeches, but should immediately open the external jugular vein, and take away as much blood as the circumstances may require. It may be done in the following simple manner :-Having carried a ligature of tape, or of any- thing at hand, around the side of the neck about to be punctured, and under the opposite axilla, sufficiently tight to make the vein rise, the integuments and platysma myoides muscle are to be freely divided by the edge of the lancet, by which the rein will be brought into view, and easily punctured. The best receiver will be a common saucer, the lip of which is to be made to press upon the vein below the orifice.

I have frequently seen the greatest benefit from this practice, which $I$ fear is too much neglected in the present day. The scalp should now be shaved, and covered with a bladder half filled with pounded ice, or snow, if at hand. The head and shoulders are to be raised, and supported in position by a hard pillow. No. 1 is to be given immediately, and No. 2 in two hours afterwards.

1.-R. Hydrarg. Chlor., Scam. Pulv. utrq., gr. iij.

Misce. Detur statim in simplice syrupo.

2.-R. Hydrarg. Chlor., gr. ij. Sacch. Purific., gr. $\nabla$.

Misce. Detur secundâ quâque horâ.

Should the convulsions not subside under this treatment, and there be reason to fear that serous infiltration has taken place, a large blister should be applied to the head, and strong mercurial ointment, spread on lint, laid along the course of the lymphatic vessels upon the inner surface of both upper arms, but under such circumstances there can hardly be any expectation of recovery.

\section{Strumous Ophthalmia.}

This disease is of frequent occurrence in crowded seaport towns, and affects children from about two to ten years of age. I have found it more common in females than in males. It cannot easily be mistaken, and is at once recognised by extreme intolerance of light, by the head being bent down to avoid it, by a copious discharge of tears on separating the tarsi, and by the difficulty of getting a sight of the cornea, which is kept concealed under the upper eyelid. There will also be a lesion of the cornea, and a red zone around it, occasioned by an inflamed condition of the sclerotic membrane.

This disease is to be treated by local bleeding, in the way of leeches or cupping, by the caustic lotion, (1), by the ointment, (2), and by the calomel doses, (3), which will, in the majority of cases, speedily subdue it.

1.-R. Argent. Nitratis, gr. iij. Aquæ Flor. Sambuci, oz. j.

Misce, et destilletur pauxillum intra palpebras bis die.

2.-R. Ung. Hyd. Nit. Cxiiłi, dr. j.

Cum quo palpebræ linentur mane nocteque.

3.-R. Hydrarg. Chlor., gr. vj. Sacch. Purificat., scr. ij.

Misce et divide in chartulas sex, quarum capiat unam omni meredie el nocte.

Very much will depend, as to the local treatment, upon the lotion being effectually thrown over the cornea, and this may be done either by a glass syringe, or by means of a silver teaspoon, to conduct the lotion between the tarsi. If these means should not succeed, removal to a different atmosphere will soon effect a cure. 
It is remarkable how long this disease will sometimes remain without destroying the vision. The two following cases will go to prove this fact.

A child, of 4 years old, and residing in a country town, had been suffering from strumous ophthalmia in both eyes for more than a year. When she was brought for my advice, the head hung down upon the chest, under a thick green veil, to avoid the light. She had been under the care of a respectable surgeon, who, I have no doubt, ordered the most judicious means for the cure of the disease, but, as they were not strictly enforced, so neither were they carefully carried out, and the result was no improvement. Having told the parent in charge of the child, that unless the lotion was effectually applied to the lesion of the cornea, and the medicine regularly given, the sight would in all probability be lost, implicit obedience was promised. On the 21 st of June, 1850 , about a month afterwards, the child was brought to me again, when I had the satisfaction to see her with two bright black eyes, free from any trace of inflammation, and the vision completely restored.

J. N., a little girl, aged 6 years, had been suffering severely with strumous ophthalmia for nine months. The eyes were intolerant of the least degree of light, were constantly closed, and guarded by a green shade. The child had been under medical advice for a considerable time, but it appeared, as in the former case, that the means recommended had not been carefully carried out. I immediately placed her under the treatment above laid down, and charged the parent, if she regarded the vision of her child, to see that the instructions were strictly obeyed. She did so, and the result was, that in a few days there was much less intolerance of light, and that in three weeks the disease was cured.

\section{Cachexia Scorbutica in Children.}

Amongst the lower grades of society children are sometimes affected with scorbutic, spongy, and bleeding gums, associated with superficial ulcerations of the membrane of the mouth, fotid breath, pallid aspect, and very low power, symptoms which have probably arisen from crowded habitations and deficient diet. This wretched state admits of rapid improvement, by the lotion, $(1$,$) the mixture, (2$,$) and a generous diet.$

1.-R. Solutionis Chloridi Calcii,

Mellis Rosæ, sing., oz. ss.

Aquæ Puræ, oz. v.

Misce fiat lotio ter die utenda.

2.-R. Quinæ Disulphatis, gr. vj.

Acidi Sulph. Dilut., gtt. xx.

Tinct. Aurantii, Comp.

Syrupi Zingiberis utrq., oz. ss.

Aquæ Destillatæ, oz. ij.

Misce capiat cochlearia parva duo bis quotidie.

The lotion should be carefully applied to the mouth and gums by means of a syringe or camel's-hair brush, unless the child be old enough to use it in the ordinary manner. The bowels are to be regulated by rhubarb or castor oil. The diet is to consist of animal broths and a little wine, and the child taken out into the air as often as the weather permits.

\section{Cachexia Verminosa in Children.}

This case is characterised by a pallid, half-starved aspect, with attenuation, picking of the nose, morbid appetite, abdominal enlargement, and lumbrici in the alimentary canal.

The cachectic condition arises, probably, from debility of the digestive functions, thereby admitting of the formation of the entozoa. The lumbricus is more commonly met with in the human body than any other worm, and sometimes a considerable number will exist in the intestinal canal of one individual at the same time. A child of 5 years old, residing in the New Forest, passed seventeen full-sized lumbrici in the course of five days. They are generally voided by the rectum, but occasionally by the œesophagus, and thence through the mouth or nostrils.

Gnawing pain in the region of the stomach, a constant craving for food, irritation of the nose, and occasional moving sensations at the upper part of the intestinal canal, more particularly indicate the presence of this worm.

This case will be successfully treated by the aperient (1), and the chalybeate (2). The former will sweep out the intestinal canal, and improve the secretions; the latter will not fail to strengthen the depraved condition of the system. A generous diet is indispensable.

1.-R. Hydrargyri Chloridi,

Pulv. Scammonii, sing., gr. ij.

Radicis Rhei Pulv., gr. iv.

Pulv. Zingib., gr. j.

Misce et sumatur bis in septimanis in crasso vehiculo.

$$
\text { 2.-Vini Ferri oz. iij. }
$$

Capiat cochleare parvum ex aquæ pauxillum bis quotidie.

If diarrhœa be present, two drops of the Tinctura Opii should be added to each dose of the Vinum Ferri, and the aperient (3), be substituted for the purgative (1).

3.-R. Hydrargyri cum Cretâ, gr. ij.

Pulveris Radicis Rhei, gr. iv.

Pulveris Cinnamoni Comp., gr. ij.

Misce fiat pulvis bis hebdomedâ sumendus.

\section{Cachexia Syphilitica in Infants.}

This depraved condition of the system in infants is not uncommon, and must have been communicated by the parent in utero. Soon after birth there is an acrid discharge from the nares, producing obstruction to the nasal breathing and constant snuffling, which occasions an excoriation of the upper lip. There is also frequently a squamous eruption upon the angles of the mouth, and condylomata around the anus. If the progress of the disease be not arrested, it will extend to other structures, and ultimately involve the bones of the palate, nose, and upper jaw. From these results the auditory function is often obliterated, and the tongue being untutored by the ear, the child will become deaf and dumb for life. This disease is curable by medicine, unless struma be associated with it, and 
there be set up a strumo-syphilitic diathesis. The mode of treatment would consist of the iodide of potassium and mercurial alteratives, the doses of course to correspond with the age of the child. In infants, the formula 1 and 2, will be sufficient for the system. If there be any eruption at the angles of or about the mouth, it may be smeared, morning and night, with the ointment, 3 ; and should there be condylomata at the anus, the caustic lotion, 4, may be applied to them twice a day, by means of a camel's-hair brush.

1.-R. Potassii Iodidi, gr. xij.; Syr. Zingi, oz. iss.

Misce. Detur infanti fluidrachm ter quotidie.

2.-R. Hydrargyri cum Cretâ, gr. xij. Pulvis Tragacantha Comp., dr. ss. die.

Misce et divide in chartulas xij.; detur una bis

3.-R. Unguenti Hydrarg. Nit. Oxidi, dr. ij.

Utetur mane et nocte.

4.-R. Argenti Nitratis, gr. $x$. Aquæ Destillatæ, oz. j.

Misce et fiat lotio bis die applicanda.

This treatment is to be continued till the disease has disappeared.

\section{Cachexia ex Alvi Fluxu in Infants.}

Cachexia in infants is sometimes the result of longcontinued diarrhœa, brought on either by a morbid secretion of the mammary function on the part of the mother, or, if it arise after lactation, by careless and improper food. The child, from this constant out-run from the bowels, is often reduced to an extreme degree of attenuation, has a senile aspect with large features out of all proportion to the shrunken appearance of the countenance, and looks like a living skelcton. Although an infant in this state may appear, primâ facie to be beyond the reach of human skill, the contrary is more commonly the fact; for, by judicious treatment as to medicine and diet, and above all, by the kind attentions of a nurse, the secretions may be corrected, the diarrhœa controlled, and the health restored. The two first may be accomplished by 1 and 2 :-

1.-R. Pulı eris Ipecacuanhæ Comp., gr. ijj. Hydrargyri cum Cretâ. gr. vj.

Confectionis Aromat., scr. j. Syrupi Zingiberis, dr. vj.

Misce, et ampullâ agitatâ, detur dr. j. omni nocte alternâ.

2.-R. Tinctura Catechu, dr. j.

Spiritûs Menthæ Pip., gtt. iij.

Syrupi Simplicis, dr. ij.

Tincturæ Opii, gtt. vj.

Misturæ Cretæ, dr. ix.

M. Detur cochleare parvum bis terve die.

The food which I have seen attended with the greatest success, is boiled flour and skimmed milk, prepared in the following manner:-Take a sufficient quantity of ftour, tie it into a linen cloth, and boil for several hours till it becomes hard; then peel off the outer part and grate the centre into skimmed milk till it becomes the consistence of gruel; add powdered white sugar, and let the child be wholly fed with it until the health is restored.

\section{Cachexia Purulenta in Children.}

The species of cachexy here alluded to, is the result of long-continued purulent discharge from external causes. The child is pale, emaciated, and almost exhausted, simply by the quantity of discharge. There is no hectic fever, and the case is curable. The following example will show both disease and treatment. :-

A child of a year old was brought to me a short time ago from the Isle of Wight, with a disease of the os ilii. It was so reduced and attenuated by the constant discharge from several openings, that there did not appear to be any rational hope of recovery ; however, I ordered fifteen drops of the Vinum Ferri to be given to it three times a day, with a nutritious diet. In a month I saw the child again, and there was a remarkable improvement, both in the local disease and in its general health; after about the same interval, it was brought to me the third tinie, when the openings were almost healed, and the child was convalescent. I am happy to perceive that the London College of Physicians has thought fit to restore the Vinum Ferri to its place in their new Pharmacopœia, as I have ever found it in the diseases of children requiring chalybeate medicine, a most convenient and effectual preparation.

\section{Cachexia Eczematosa in Children.}

This disease is very common amongst the ill-fed and neglected children of the lower classes. There is a pale and sickly aspect, and on different parts of the scalp the hair is matted together with filthy scabs, of eczematous secretion, from which exudes a thin and irritating discharge. There are also weak ulcerations behind the ears, and about the angles of the mouth, and on the nares, \&c.

There is no eruptive disease more easily got rid of than this, provided the treatment be carefully carried out. The whole of the scalp having been closely clipped, and the scabs removed by poultice or fomentation, the eczematous parts are to be smeared by the ointment, 1, twice a day, and well fomented before each application. The alterative dose, 2 , is to be given twice a week, and the strength supported by 3 . By these means the removal of the disease will be at once accomplished.

1.-R. Unguenti Hydrarg. Nit. Oxidi, oz. ss. Bis die applicanda digito.

2.-R. Hydrarg. cum Cretâ, gr. iij.

Pulv. Rhei, gr. iv.

Pulv. Cinnamonii, gr. j.

Misce fiat pulvis bis hebdomedâ sumendus in theriacâ.

3.-R. Quinæ Disulphatis gr. ij.-iij.

Acidi Sulphurici Dil., gtt. vj.

Tinct. Aurantii, Co.

Syrupi Zingib. sing, dr. ij.

Aquæ Destillatæ, ad oz. iij.

Misce capiat cochleare largum bis quotidie.

Southampton, Nov. 27, 1851.

[To be continued.] 